
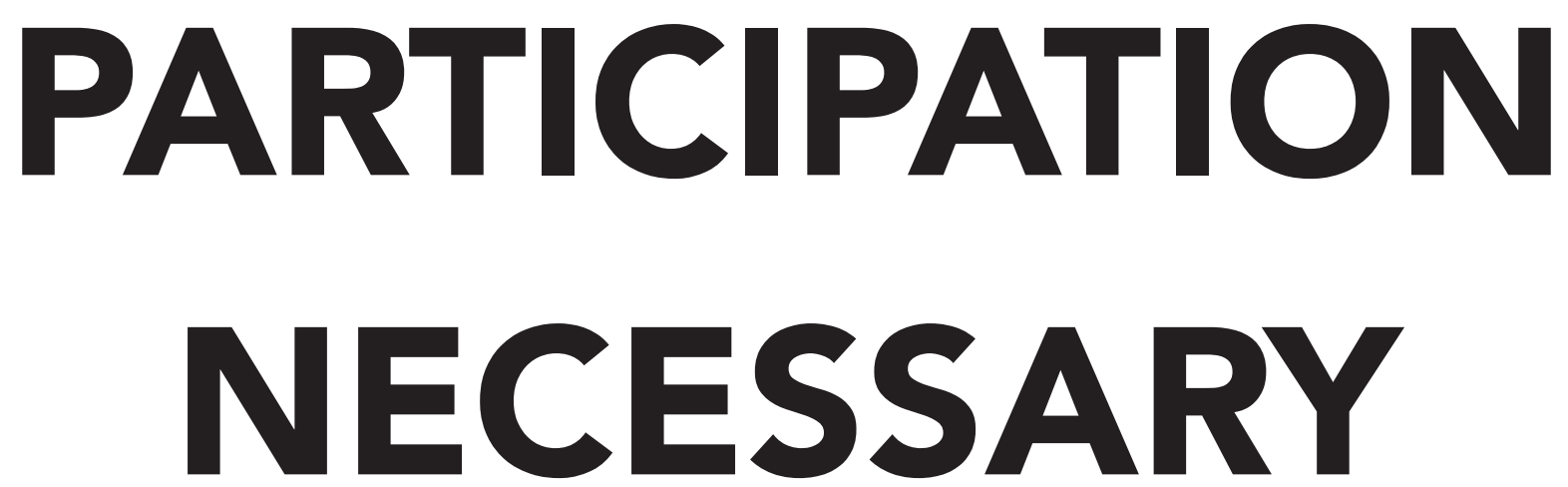

\title{
AN INQUIRY INTO A MOMENT IN TIME AND SPACE
}

\author{
by \\ Brock Klassen
}

A thesis submitted to the Faculty of Graduate and

Postdoctoral Affairs in partial fulfillment of the

requirements for the degree of
Master of Architecture
in

M. ARCH (Professional)

Carleton University

Ottawa, Ontario

(C) 2016

Brock Klassen 


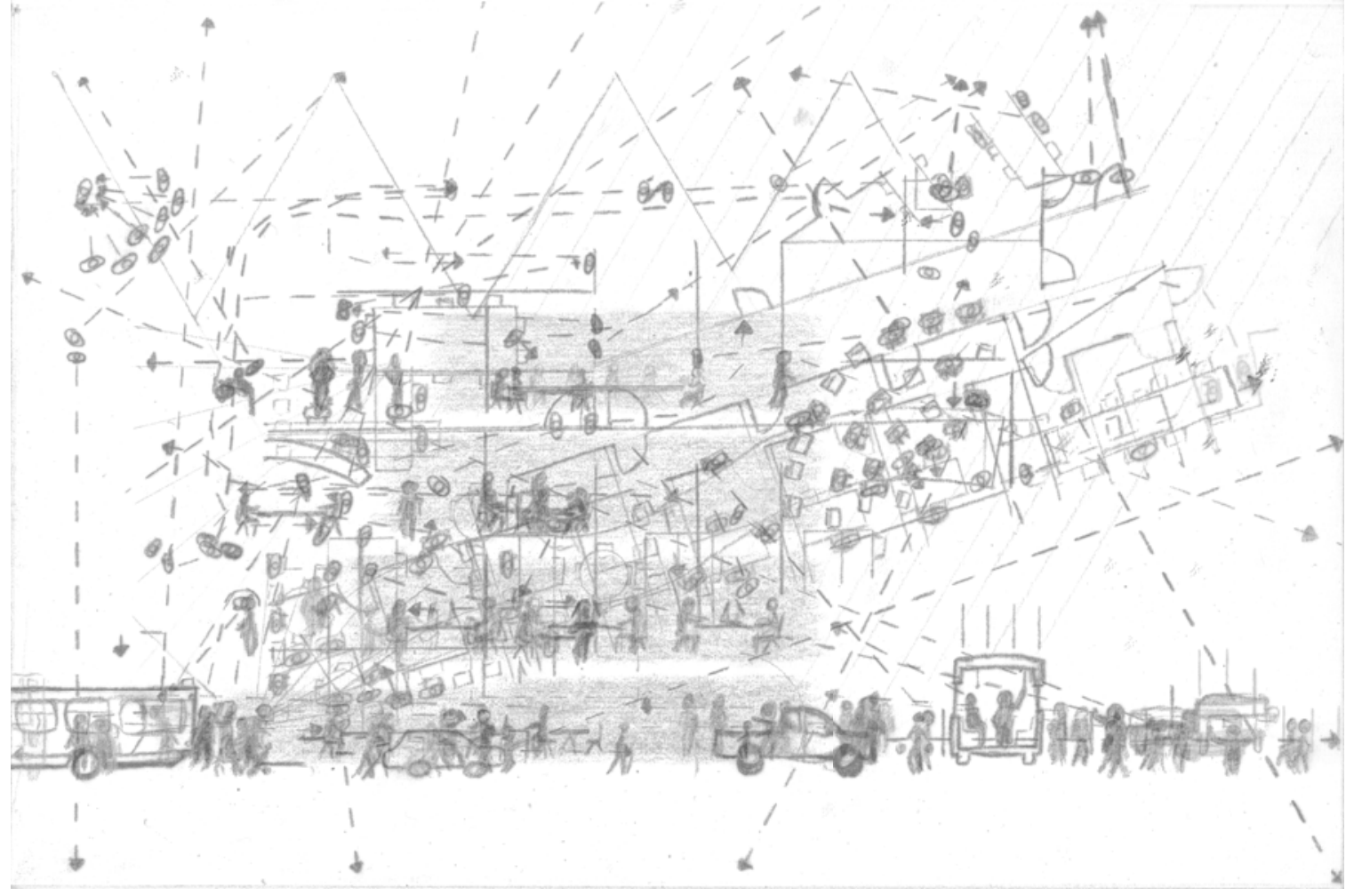

\section{Abstract}

This thesis-as-project (project-as-thesis) is an inquiry into the human connection with the world, it asserts that the occupants of space have a critical role to play in the creation of architecture. Through in depth research and creative writing an understanding of the embodied experience of the built environment, and the architects' impact on this experience is undertaken. A selected site and program are used in an attempt to engage more concretely with the issues at hand. The work is organized by three major interconnected trajectories of thought, which are either read independently from one another or as a whole. The process of deriving a potential architecture is, in this thesis, the project, a 'stream of consciousness' architecture. These non-linear trajectories form a critical interrogation of the role of the architect.

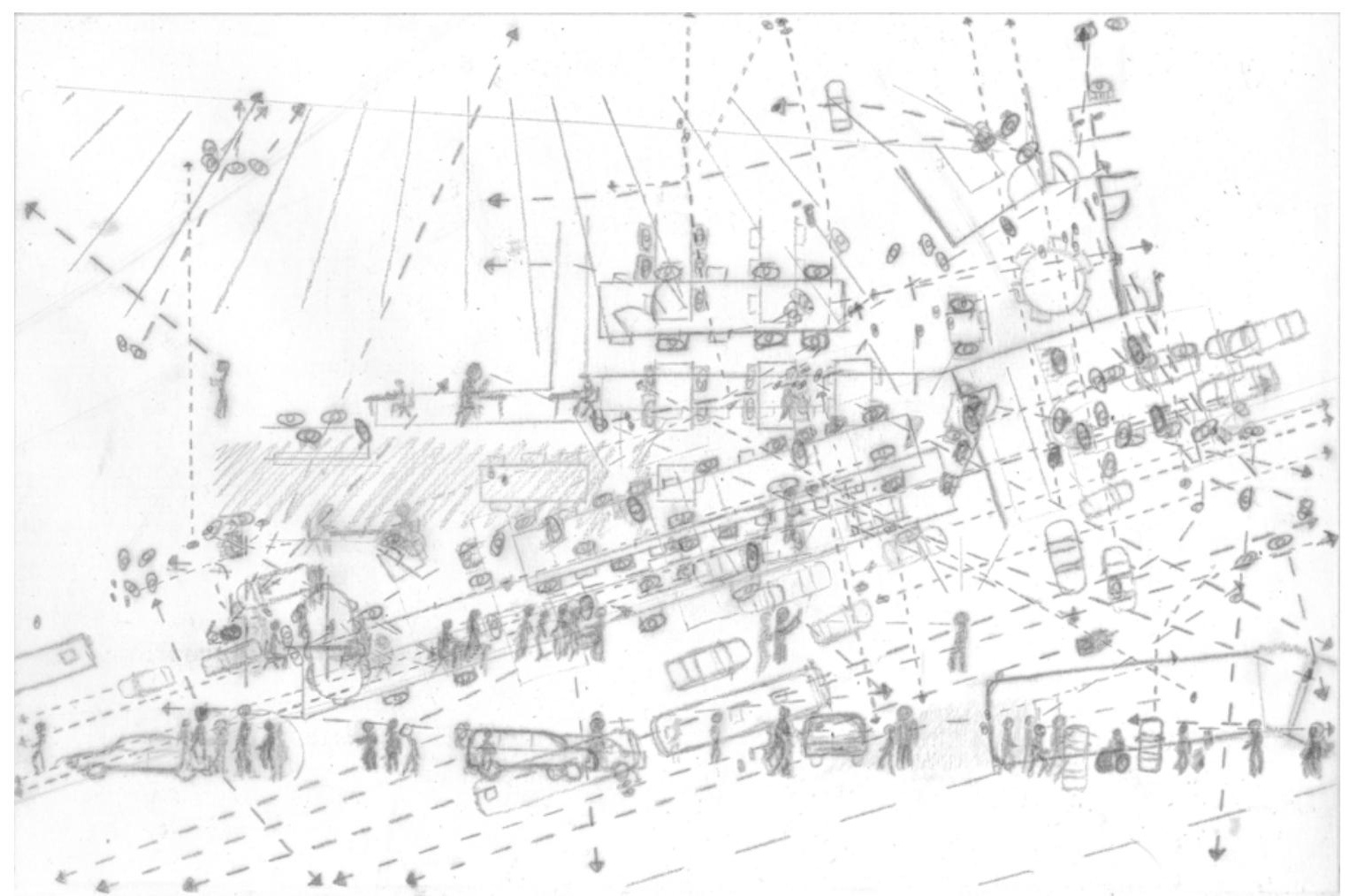


To my wife, Gillian Harlos Klassen 


\section{Contents}

Portfolio I Liminal Play

Act 1 I Rules of Engagement

Act 2 I Body Texts

Act 3 I Non-Optional Potential Architecture

Intermission I Doubt

Act 4 I Two Guys Walk into a Rendering (stop me if you've heard this one)

Act 5 | Build out of Dwelling and Architecture arrives

Act 6 I Initiating (Mundane) Thresholds

( $10 \times 30 \times \infty$ Potential Architectures)

Post-Script I The unreading architect 


\section{Portfolio | Liminal Play}

Liminal I adjective | lim-i-nal

1: of or relating to a sensory threshold

2: barely perceptible

3: of, relating to, or being an intermediate state, phase or condition

(Merriam-Webster Online)

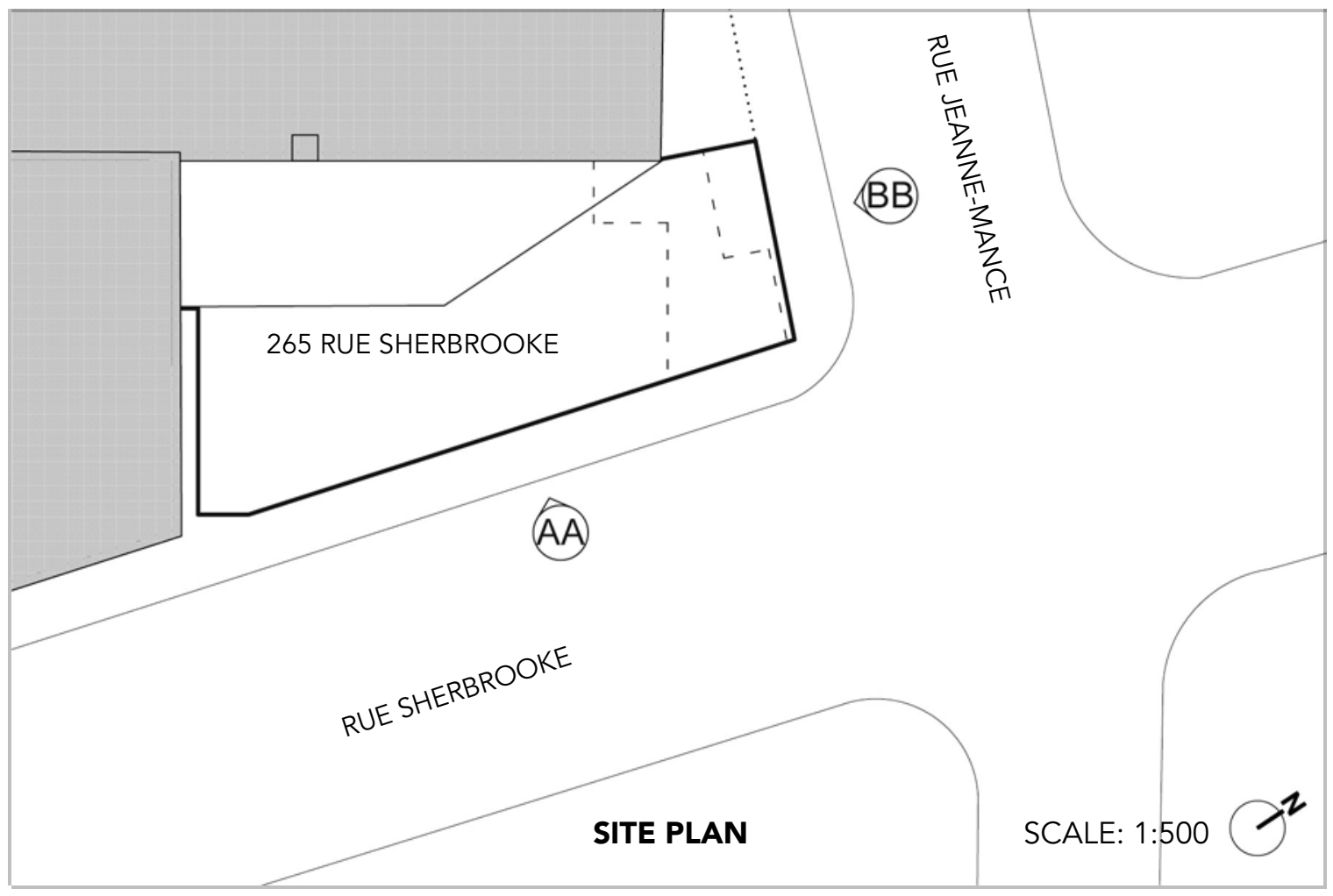




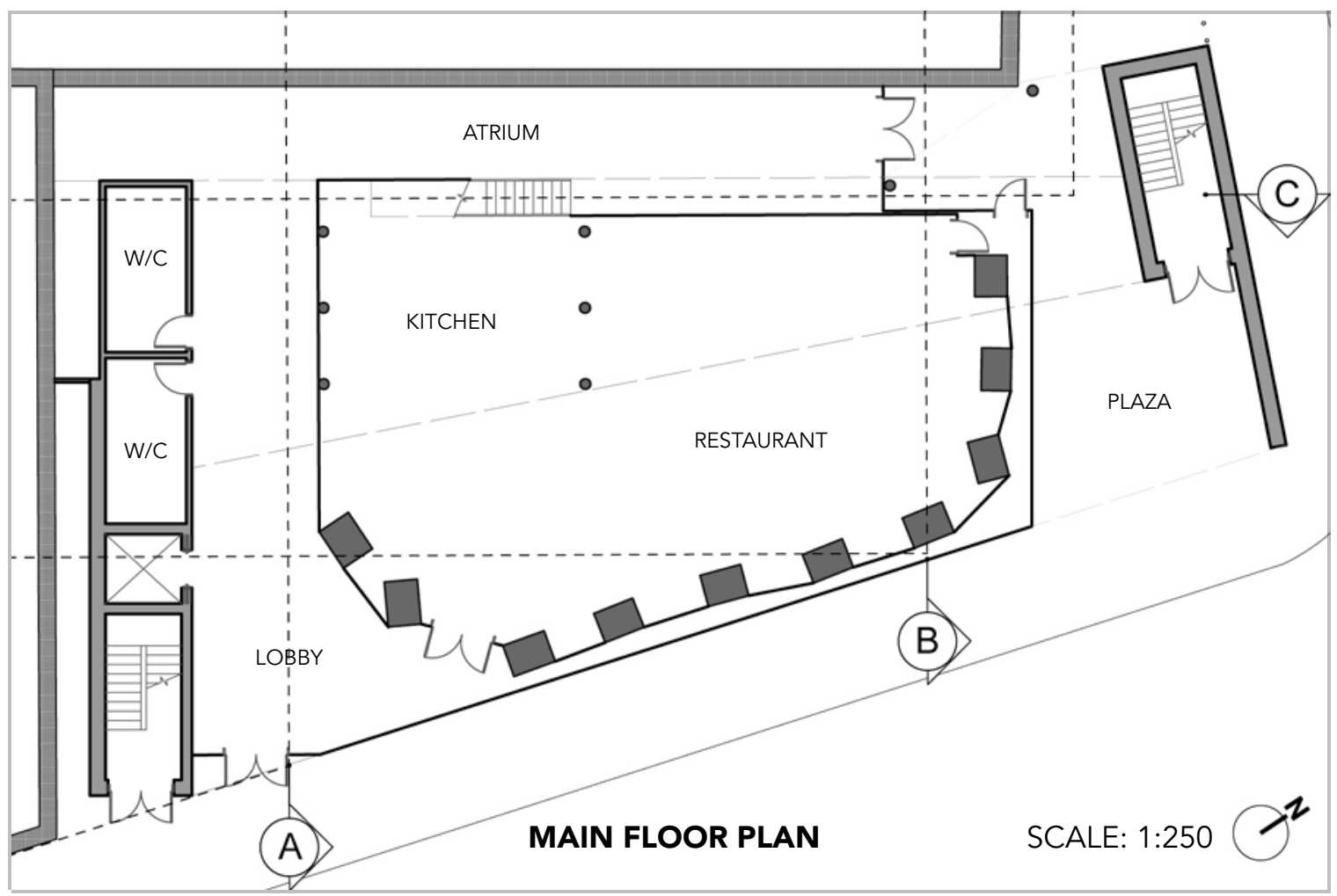




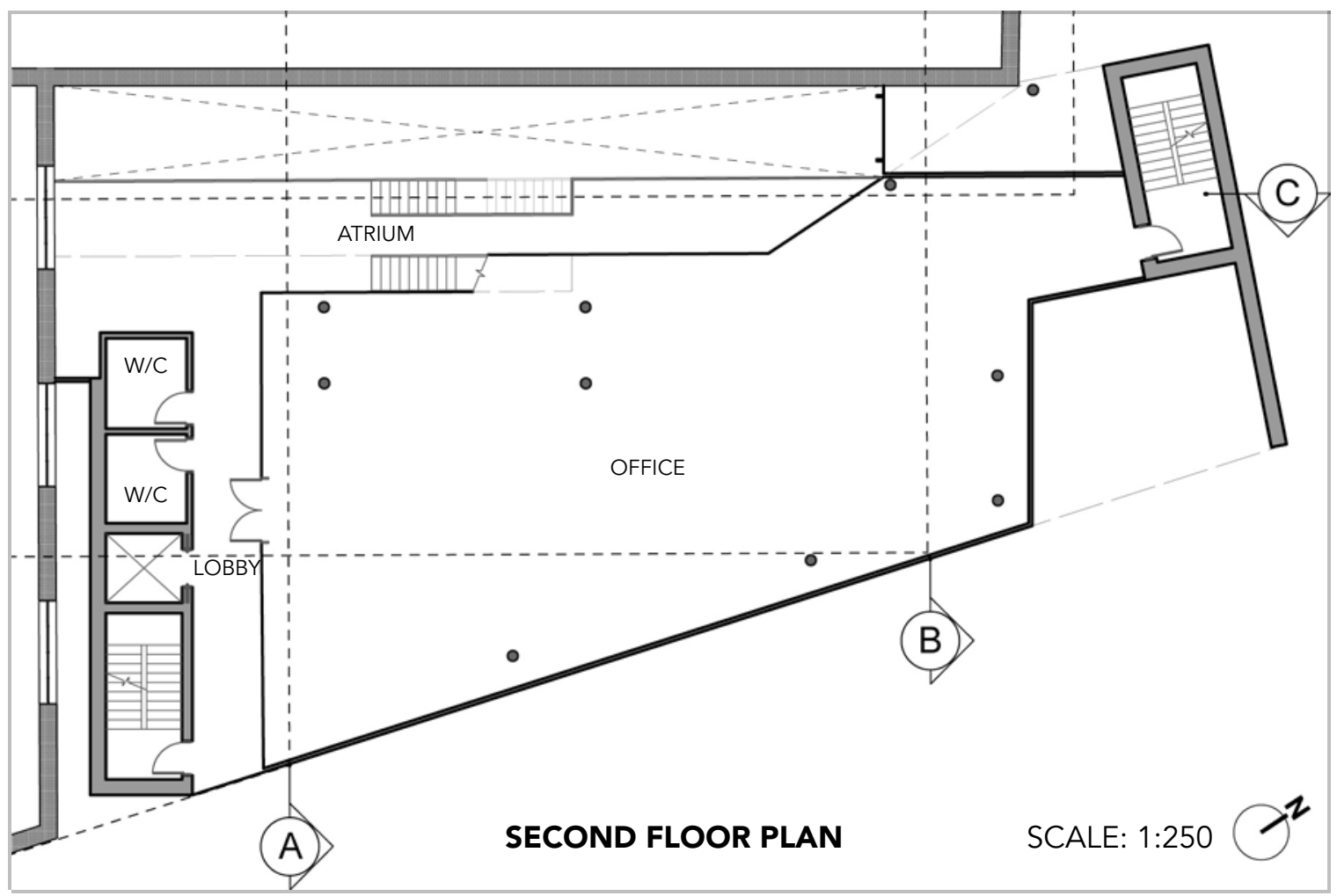




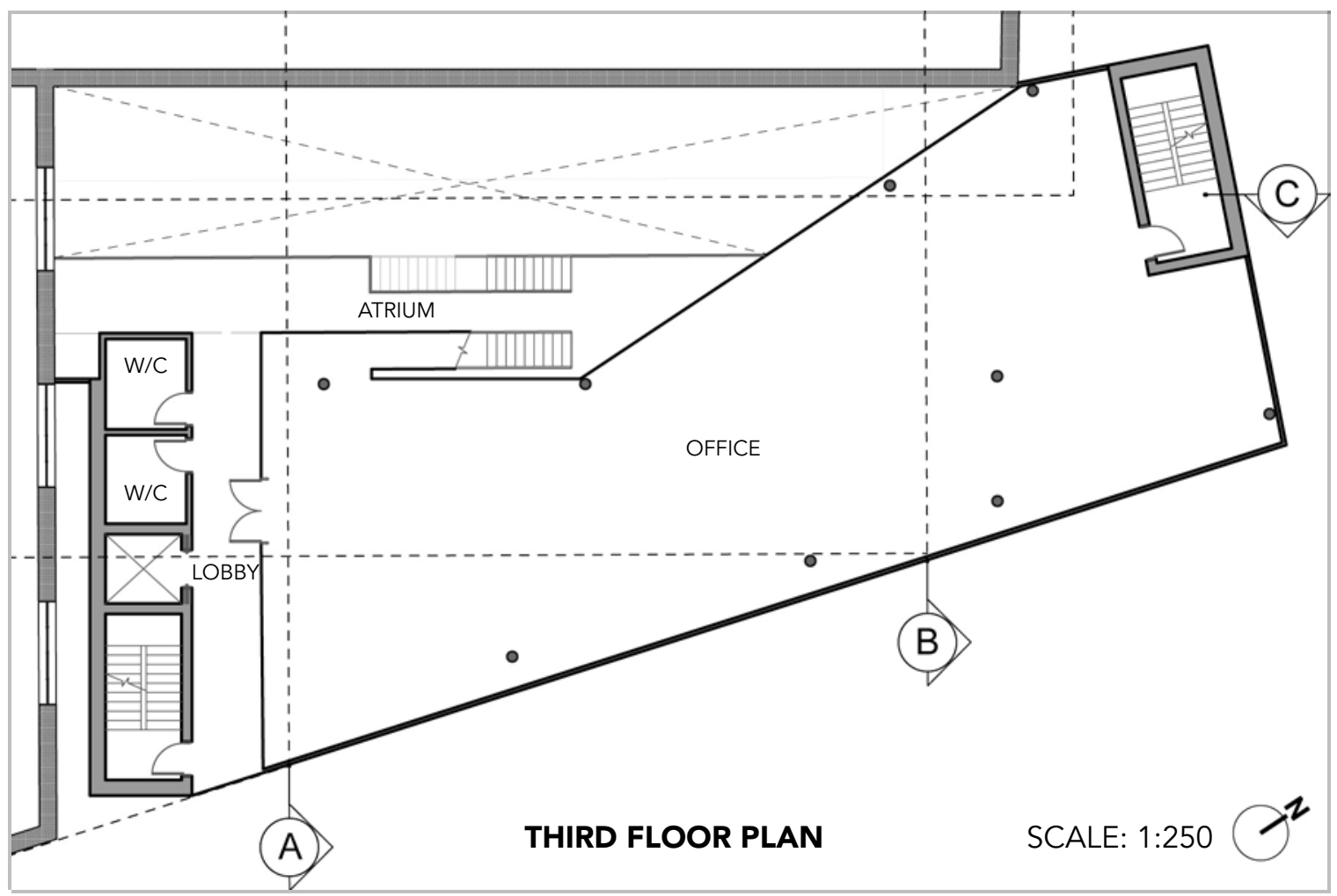




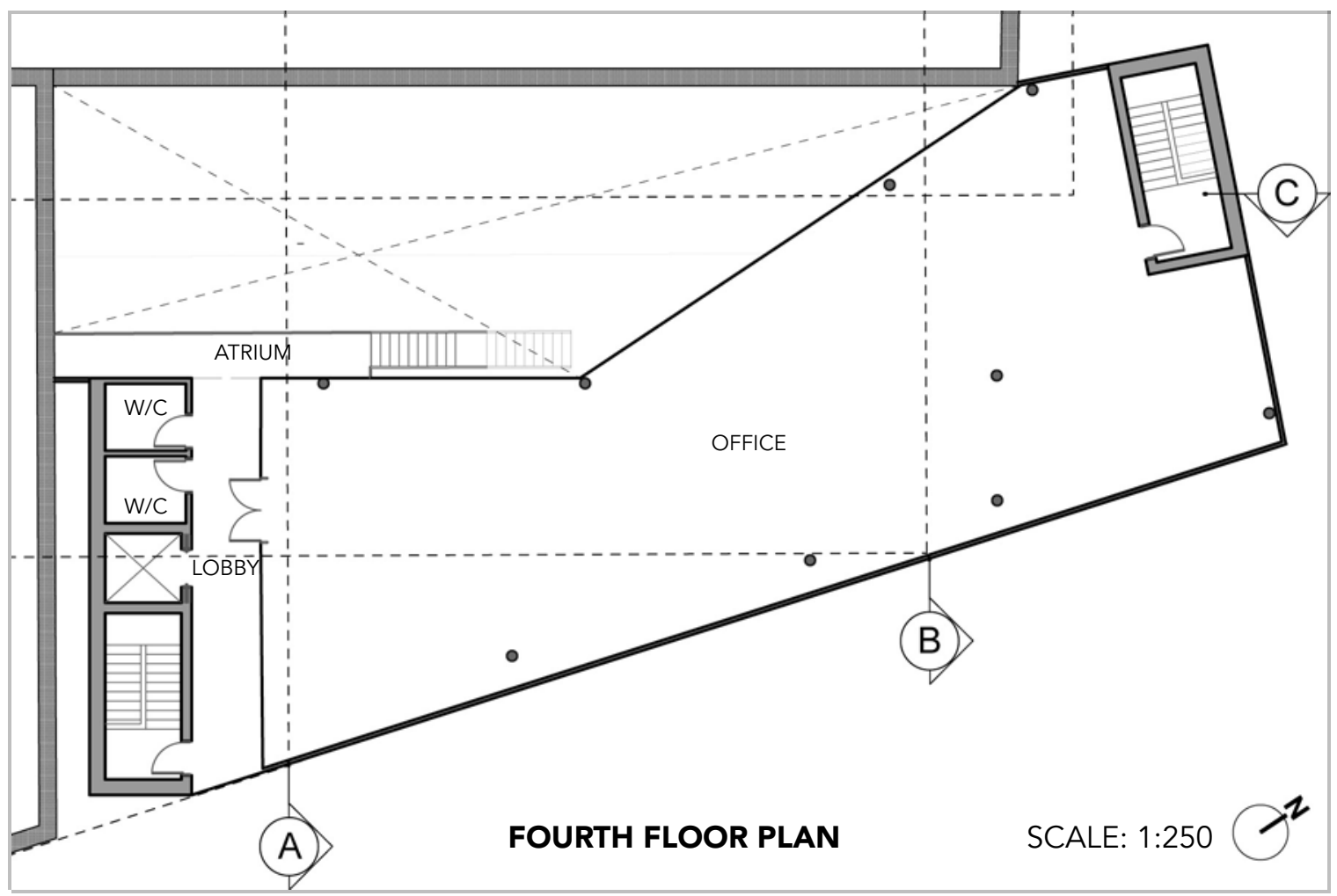




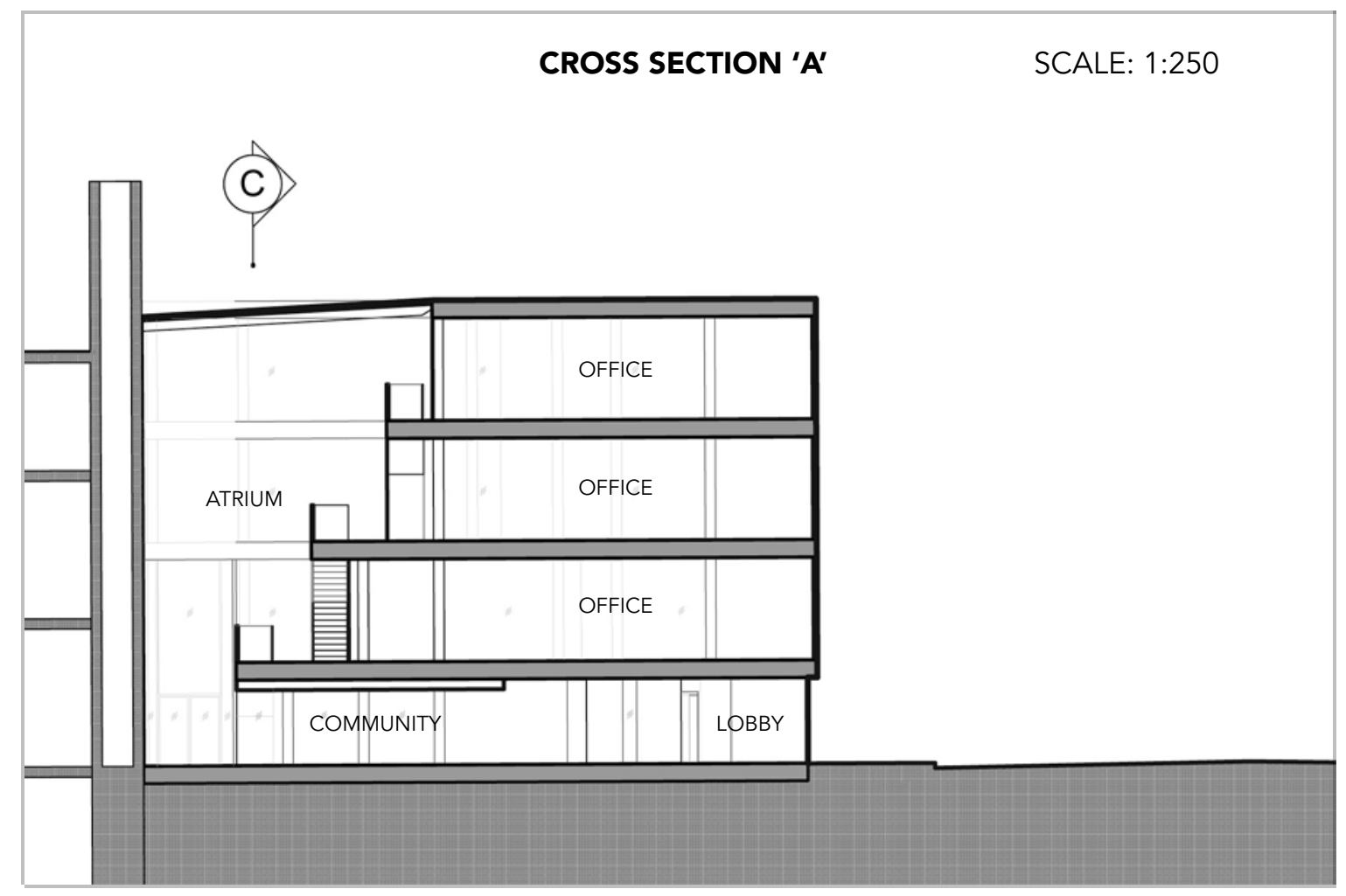




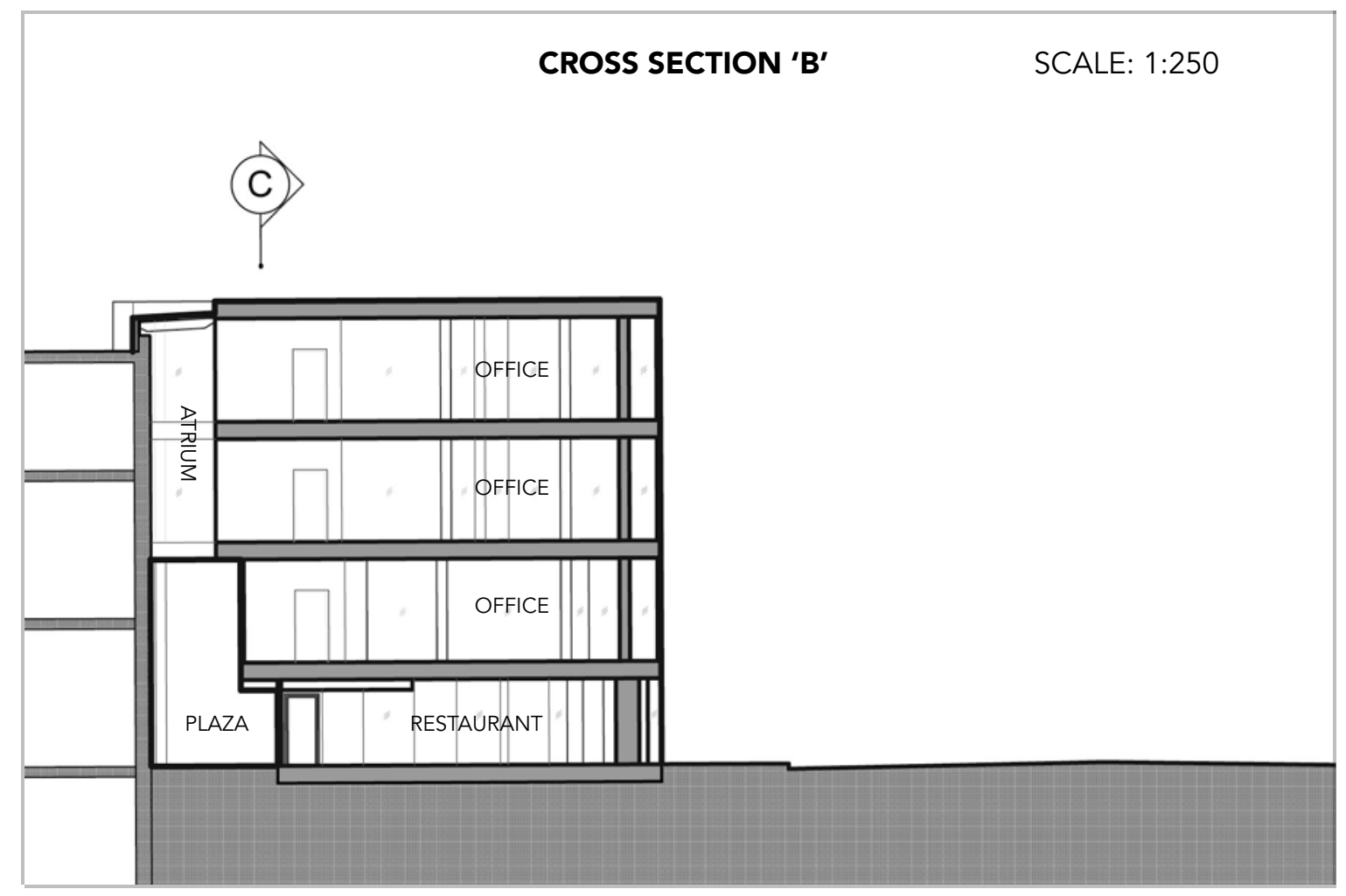




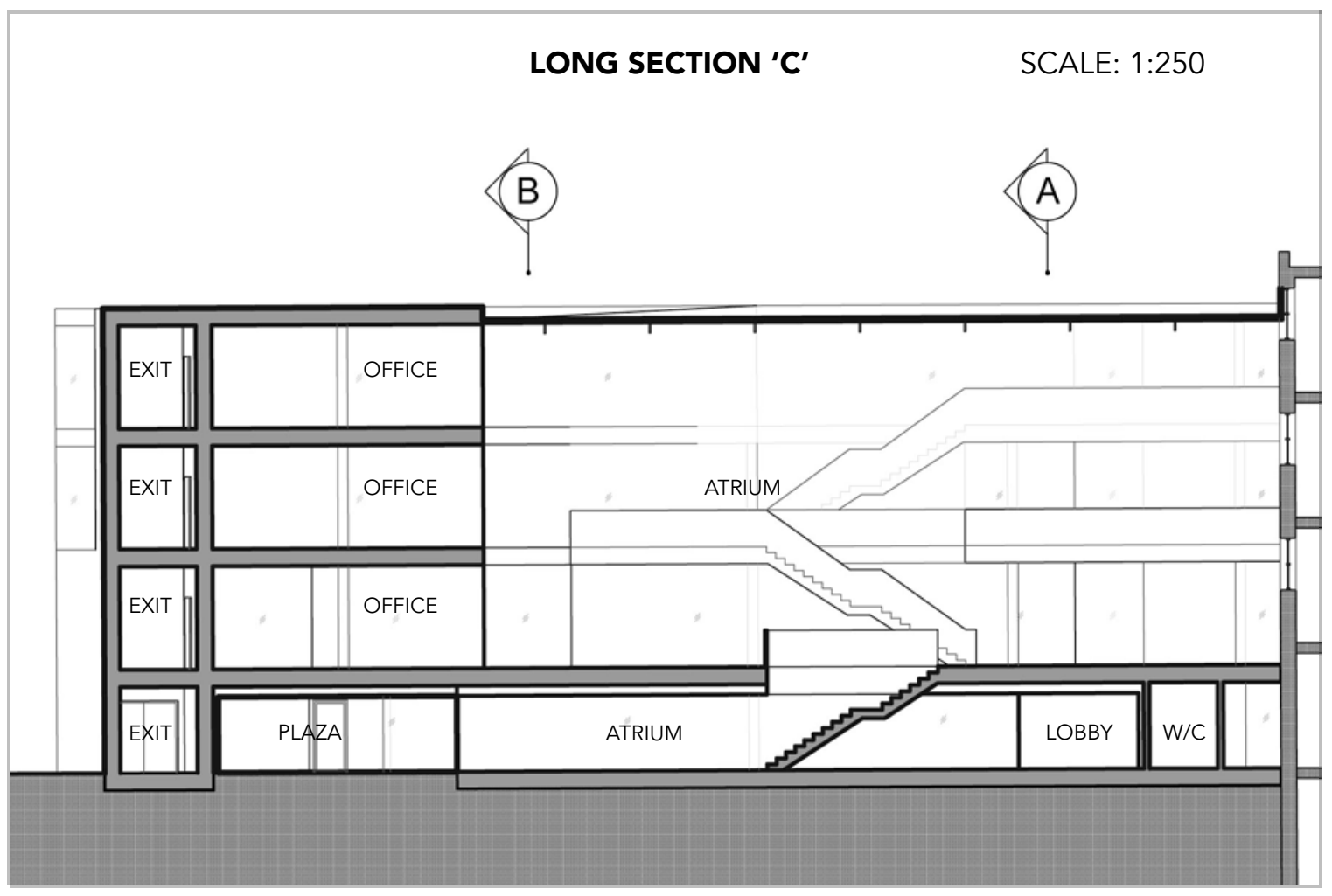




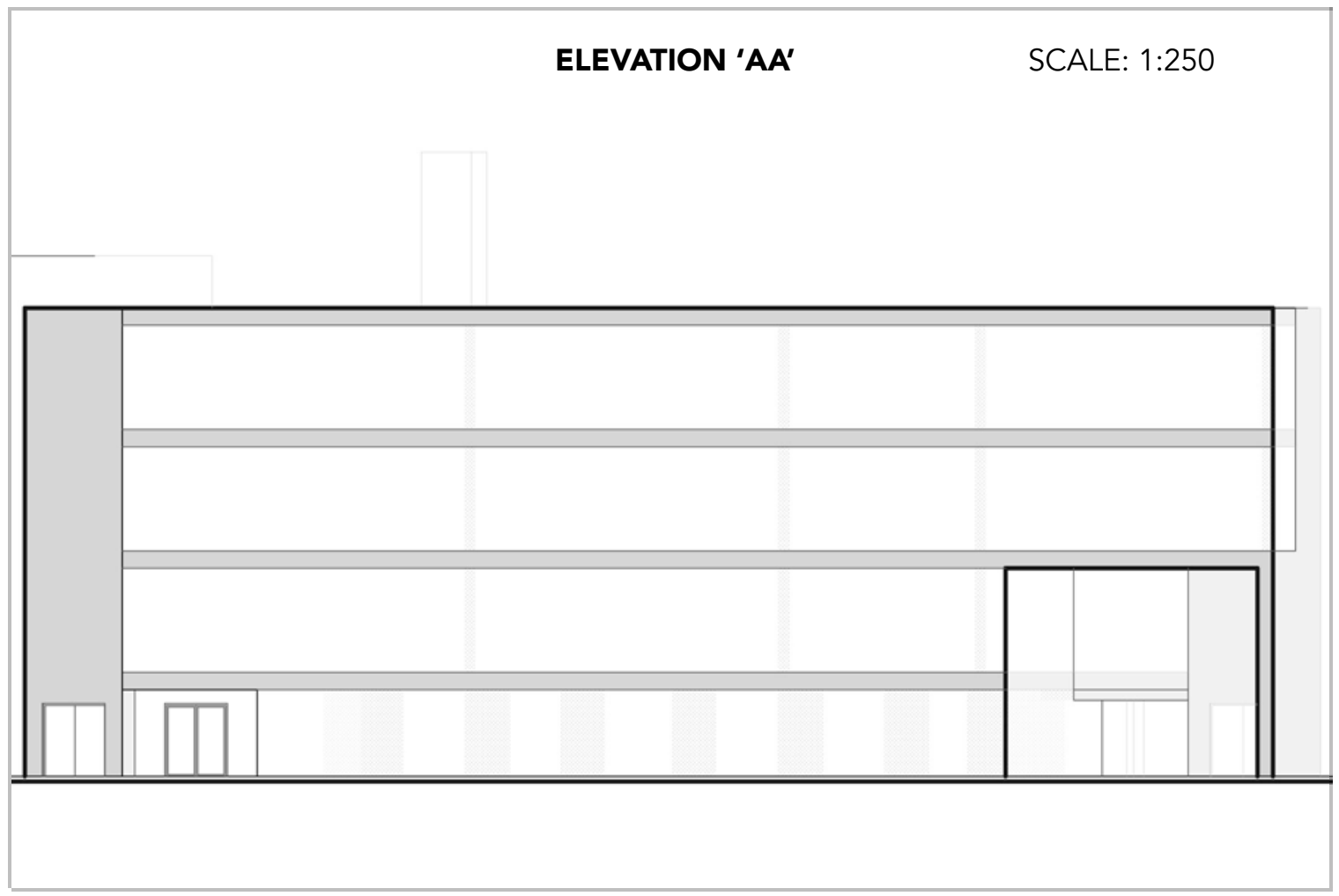




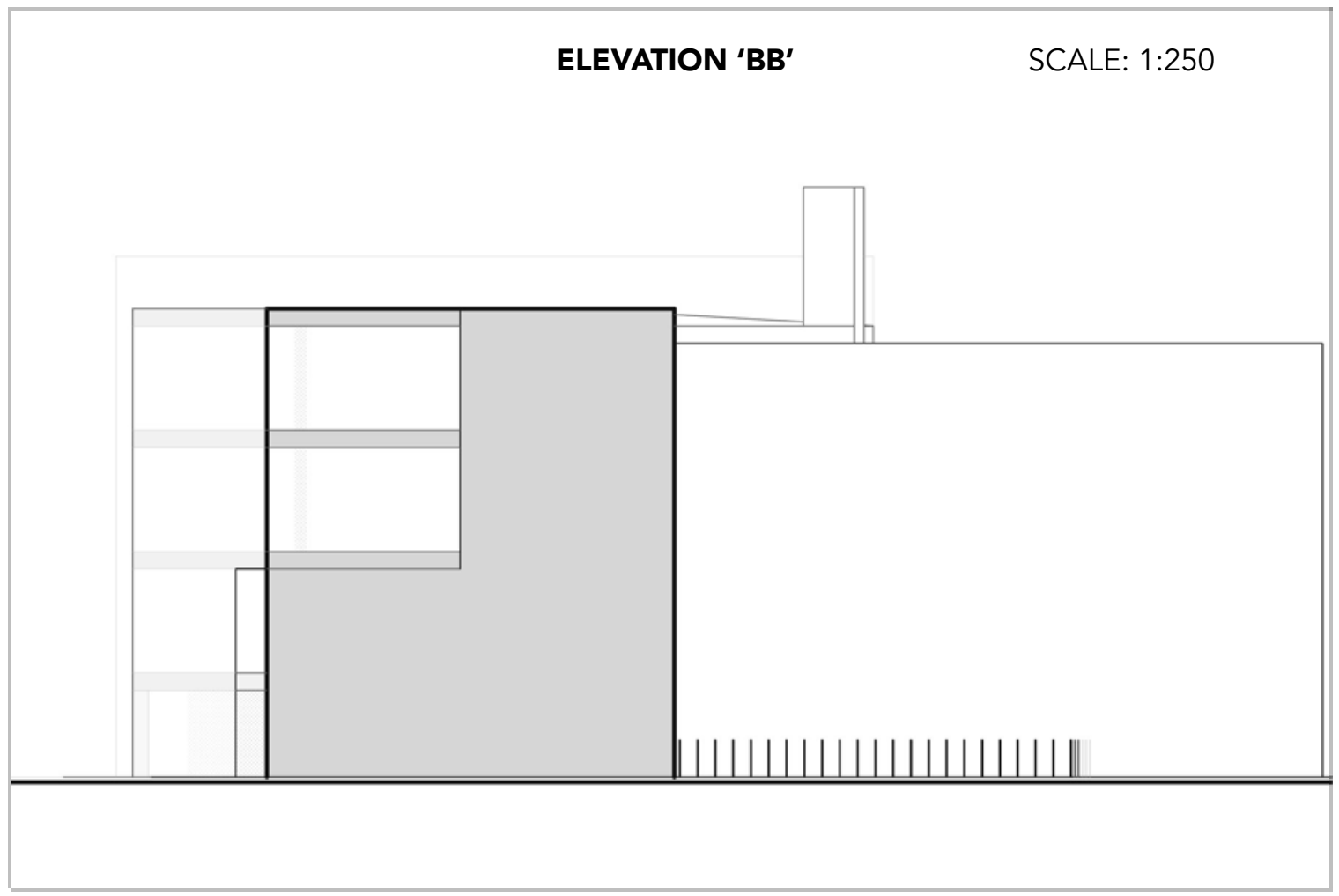



$65=0.5-1$ 


\section{Intermission | Doubt}

We of the Manifesto

I of the Stage Play

Passive of the Essay

I'm beginning to think that perhaps the chosen site is too small, maybe this project is better considered at the scale of the city?

How can an Ongoing Manifesto be projected onto multiple sites at one time? The purpose of this is that an equally compelling Manifesto plays out in every moment of our mundane and daily lives; we have been considering a specific circumstance as a way to reveal our role in the creation of architecture. It is not about one site, or many sites, but every site; and the inherent uniqueness of each moment in time and space.

Indeed this project does not propose a grand new solution for architecture, but rather works backwards from grand conceptual drivers in order to reveal an architecture for a specific site that may challenge people to live to their fullest. It is correct to state that this work is an investigation of conflict, it proposes provocations rather than solutions. The question that eludes this explanation is which types of embodiment are being investigated?

Well, we have noted that each individual sees the world from a different point of view and that while we are all unique we do have a common way in which we exist within the world. By invoking Claudio Sgarbi's list of varied bodies in Act 2 we attempted to assert that while humans have an undefinable number of differing ways in which we each physically exist in the world, we are attempting to investigate generally how we live in the world through our bodies. We use the 
notion of embodiment as an attempt to understand how the built world affects us, and how it is affected by us.

For my part I have been using my own experiences to catalogue meaningful bodily experience of the site. While in no way are these investigations exhaustive of the possibilities of interaction between people and the site, they can give us general clues as to the opportunities for architecture currently available. The friction between the architect in the studio and the person on the street will always be present. These explorations attempt to close the gap between the view of the architect of the building and the view of the inhabitant of the building.

This is a particularly interesting discussion in relation to recent neuroimaging studies in which architects and non-architects recorded similar brain activity when looking at other people, but registered significantly different results when looking at images of buildings (Mallgrave 45). These findings suggest that the experience of these two groups are incompatible, that they are wired differently on a fundamental level and the difference needs to be reconciled if architects are to continue to have relevance.

This need for reconciliation is exactly why in this project I start by considering experience on site and then intend to propose an addition to the built environment. It is important to keep in mind that the architect is always removed from the immediacy of the situation when they design, this is the curse of the architect. Thus, I need to be aware of my own subjectivity, which is undoubtedly shaped by my embodied experience. Speaking of which, should Maurice Merleau-Ponty really be my primary source on embodiment?

Merleau-Ponty is one of many sources being leveraged to better understand the essential human conscious experience of the world. His theories offer diverse and detailed insights 
into the ways in which we exist in the world through and as our bodies. His work is also referenced by many who are currently studying embodiment and its' rspecific elation to architecture, which is why Merleau-Ponty's views on phenomenology are an interesting place to start the conversation.

We have been purposefully mish-mashing sources since many authors can offer insights for our subject. By bringing together a wide range of voices we can begin to organize a well-rounded argument for embodiment. Our task moving forward will be to draw our sources through the work, to bring them with us as we proceed rather than leaving them behind, in effect to try to consolidate our many voices into an informed position.

But drawing on notions of embodiment alone may leave the project suspended, how is the work being grounded with a specific urban issue?

I have been clear about my intentions to propose a building from the beginning. A mundane site (265 Sherbrooke Street West) and program (office building) have been purposefully chosen to highlight the notion that these are not ideas that belong to grand projects alone but exist in every moment of daily life. This project is also about the role of the architect; I am pursuing a unique process and hope to better understand the position of the architect in the creation of meaningful architecture through this process.

We have been using embodiment to better understand the relation of people to the built world, in a word to better understand architecture, but it is one of several tangents running through the project. One of our goals is to reveal our role in the creation of architecture, to reveal how embodied persons are relied upon for architecture to exist. A play relies on the actors to animate the stage.

The analogy to theatre is helpful in understanding the way I have been 
conceiving of architecture in this project. This way of thinking inherently privileges the people inhabiting the buildings, the form of which I intend to design in order to fit their needs. But I'm beginning to think the focus has been incorrectly placed, should the script be revealed rather than the play itself?

This may enable the curtain to be pulled back more effectively, revealing more certainly the friction between the actors and the stage and the role of the architect in directing this interaction. If the revealing of the script is to be preferred, then the human figure needs to be considered more intently in the architectural drawings. How can the figure become a part of the architecture of the drawings rather than simply occupying space? This is very much related to a search of how people can be "more than mere inhabitants of the city?".

Well in the most recent drawings of Act 3, the figure in the drawings was the viewer. Part of my purpose in using perspectival projection was to implicate the participation of the viewer and thus reveal/discover the site in the first person. At the same time I was concluding that real experience cannot be found this way, only a representation of real experience. So you may be right, maybe the drawings need to suggest the figure as a part of the architecture and let the audience simulate the play themselves.

We think that maybe it is time to become escape artists. We need to escape from the perspectival view, we need to escape from the reductive normalization of the body, we need to escape from the conventional practice of the architect. Once we have escaped then maybe we will be able to redefine the respective roles of the Embodied Persons and the architect.

I like this very much.

This work inherently has a tragic ending. 
ond $=3$

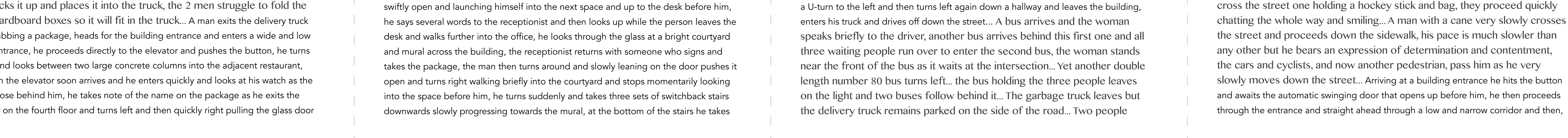
$\underline{=}=$ $\underline{\underline{1}=\mathrm{V}}$ 


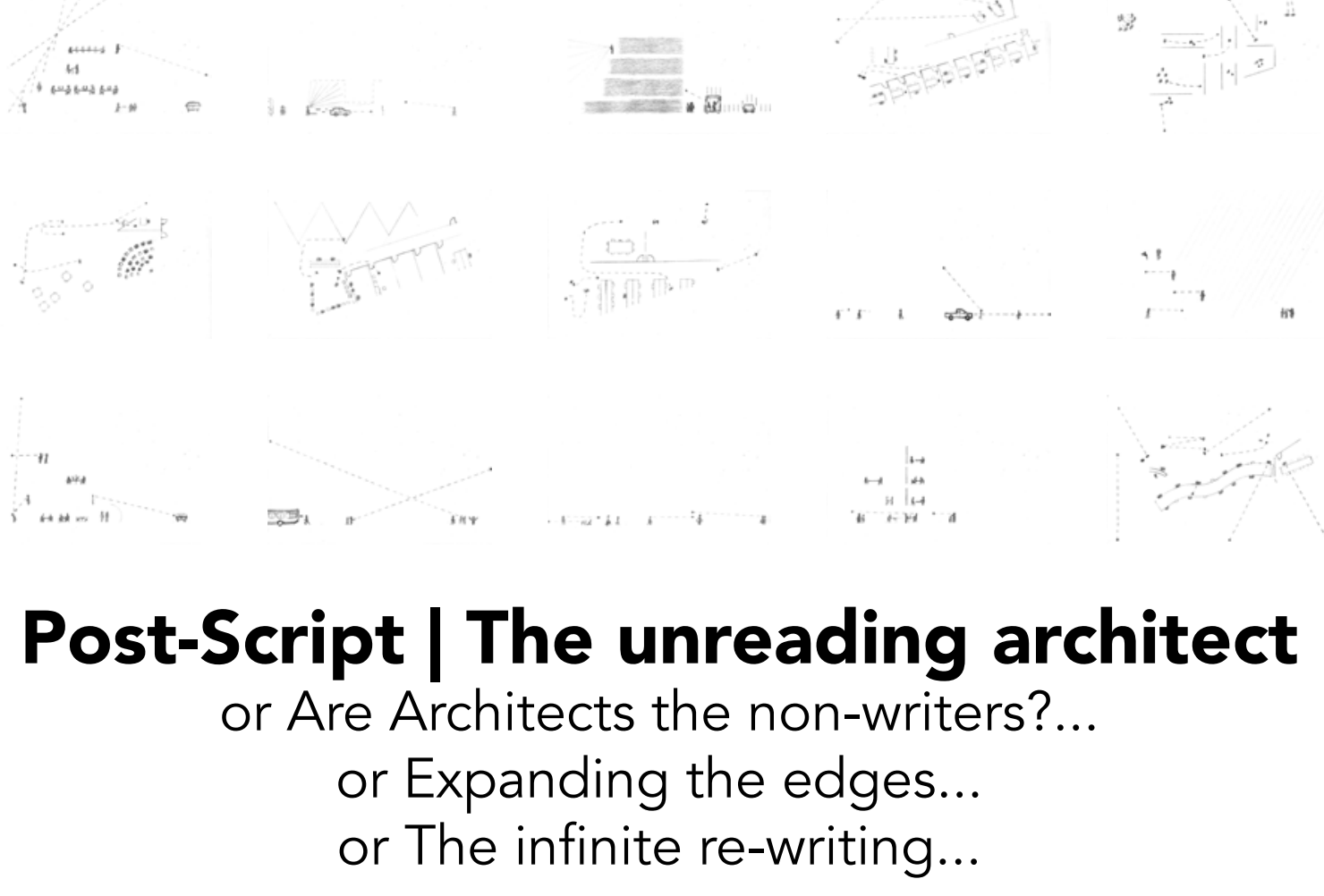

If you are not reading this, you have already proven my point.

This project does not propose solutions, not really; it rather investigates how the role of the architect can be expanded while simultaneously reducing the power wielded by the very same Architect. In this case, the participation of people, who become actors and play an integral part in the creation of architecture, was studied. An exploration of embodied consciousness in space in a specific circumstance led to the establishing of a script for Potential Architecture, rather than a preconceived play.
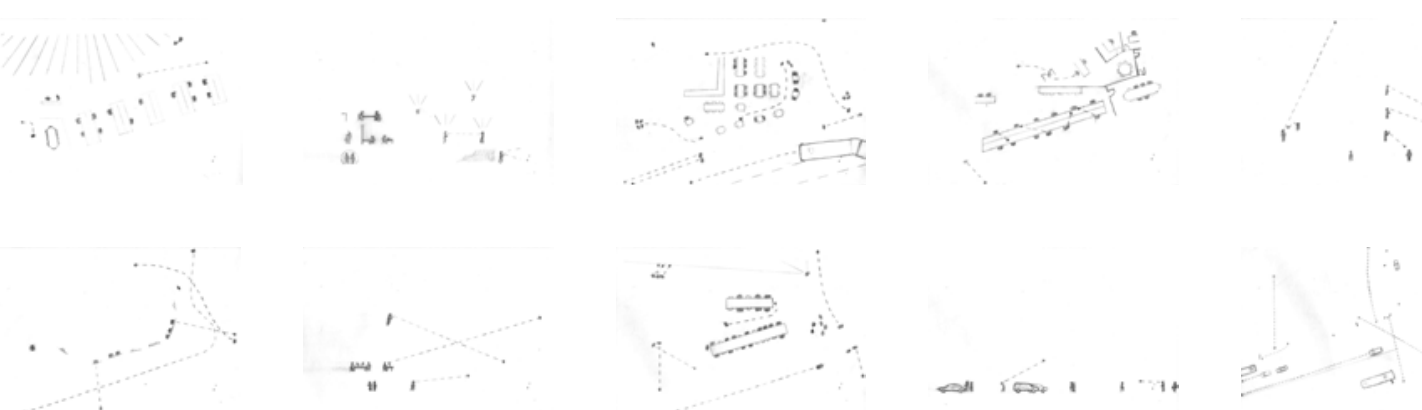
It began with a leap of faith, a beginning with no idea of an ending. A peculiar type of dérive or wandering for which a destination was unknown and in continual flux. This process led to an informed position from which a built proposal (the Portfolio) was established. Act 1 set up the methodology, rules and definitions applicable to the process. Act 2 and Act 3 investigated the embodied experience specific to this moment in time and space. Then the Intermission disrupted and re-considered the ongoing process, after which Act 4 reflected on difficulties confronting contemporary practice and tested these difficulties on the site. Act 5 was used to establish a major design response to the site and circumstance while Act 6 explored the implications of this response and refined the proposal. Each Act fits into the larger narrative but also stands alone.

The process of discovering remains the most important thing.

The three Trajectories and the six Acts are meant to be read either consecutively, simultaneously, randomly, altogether, alone or however one chooses; the choice is the reader's. At the same time it is hoped that each reader will interpret these scenarios for themselves, and define them according to their own subjective desires and purpose. This would mean that every participant reads a different thesis, and subsequently I am already beginning to relinquish control.

For example the drawings of Act 6... Drawing inspiration from Bernard Tschumi's Manhattan Transcripts, these drawings are an investigation into the Potential Architectures inherent to the built proposal. The participant is meant to attempt varying configurations of the scenarios of inhabitation as they relate to the drawings of the portfolio as an act of Stage Play. The accompanying texts are observations of real life on the site (see Act 2) which is then fragmented by imagined fictions in which people dwell within the proposal; effectively disturbing the historical record.

In essence real people and their actions are being used to animate a fiction in an attempt to better understand and embrace the implications of human inhabitation and its inherent indeterminacy. The reader then uses these drawings and text to enact their own architecture, albeit within themselves; a direct metaphor to the way Embodied Persons courageously inhabit real space. 
It is always-already not enough to simply slip images of people into fantastic visualizations of never-to-be-realized buildings. Firstly, people do not exist as images, but rather as living beings consciously engaged in space. Secondly designing a building in a virtual world from the building's point of view cannot account for the complex relationship of people in space. And lastly even if the building is built as it is drawn, current rendering practices ensure that the building will never live up to the advertisement, and clients are left imagining a different building than they inhabit. To subvert this we thoroughly research our actors and consider the ongoing and ephemeral experience of the site from the perspective of those who inhabit the space and create the architecture. We acquire knowledge and understanding through a creative/fictitious, although very real, process. Instead of approaching buildings as conceptual and formal problems to be solved we situate ourselves (and allow participants to situate themselves) within a 'stream of consciousness'.

What if Vitruvius is right, what if knowledge is like a body? If so, then a body of work should be subjected to the same rigorous remaking as we are in our lives. And if knowledge is not a set of unconnected experiences but also a single living cohesion, then we cannot accept this project for anything beyond this site and program in the year 2016. We may even wish to re-write every chapter as new ideas become explicit, for certainly this search has not been exhaustive and could still be taken in many different directions.

If this project was conducted with a different site or program, in a different year, with different inspirations or by somebody else we can certainly conclude that the result would not be the same. There is an infinite number of possibilities; what is important is the chase, the journey towards better understanding. And so the Ongoing Manifesto is meant to be absorbed, appropriated, changed and returned, it is something we do every moment we inhabit the physical world and it needs to be done with this work as well.

In December 2015 I received the feedback that this work would inherently have a tragic ending. But given the ephemeral nature of knowledge and understanding I would prefer now to indicate that if this work were to end, then that would be tragic. So we go on reading... and participation is necessary! 


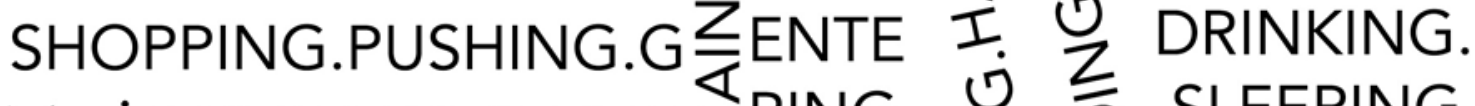
细ING.RETAINING.RETRING 空

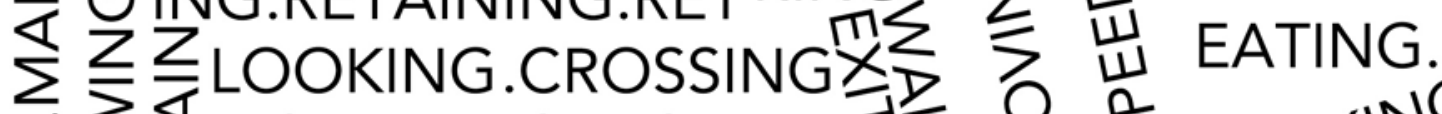

i. Z 온

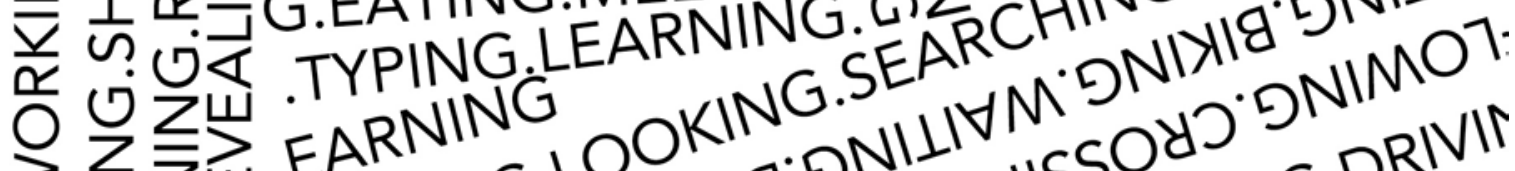

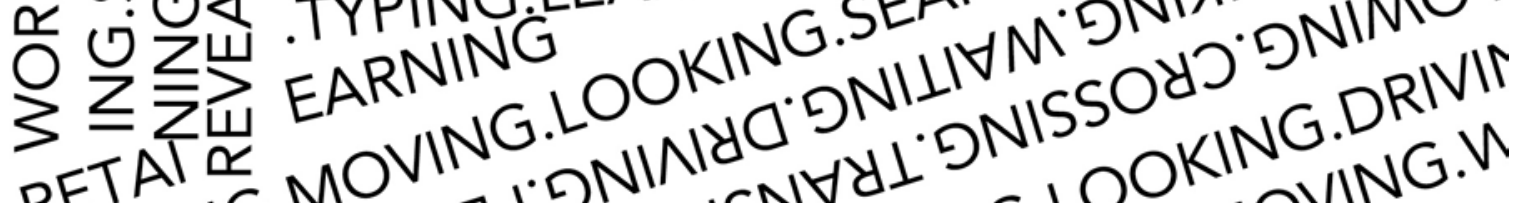

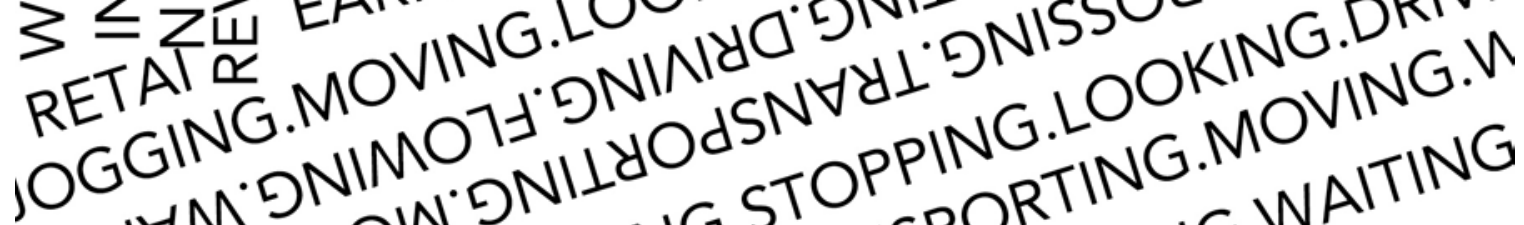

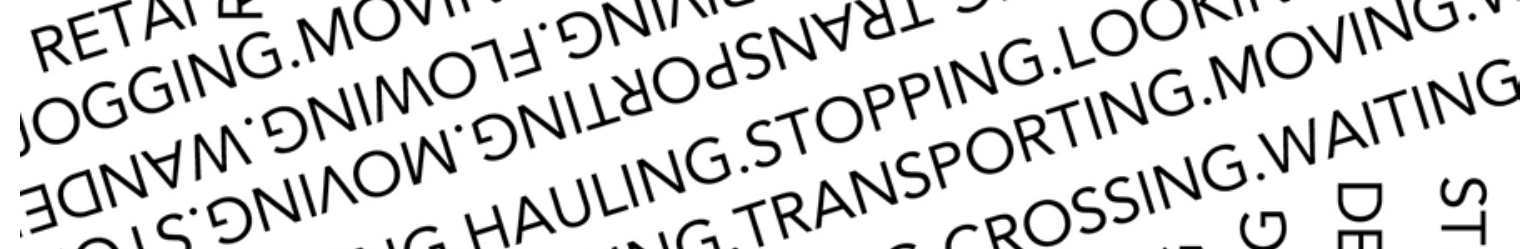
IDOLS DNATANG.HAULLNG.TRANSPORTSSIN ACEELERATINGMMUMUTIN DRIVING. INALKNG. DR

¡HOPPING.EATING.GRABBING.PAYING דGUARDIN IINSPIRING.CONTRIBUTING.CROSSING 总罗

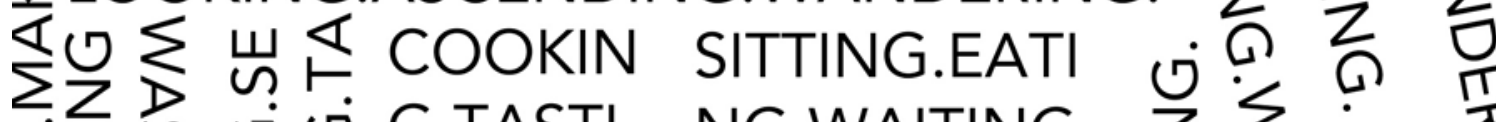

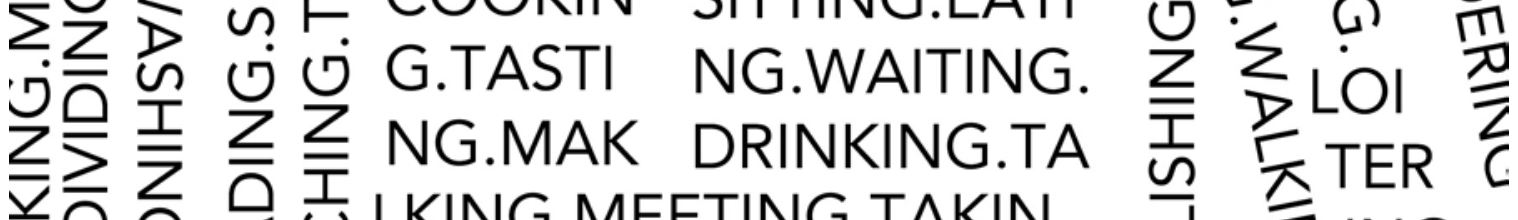

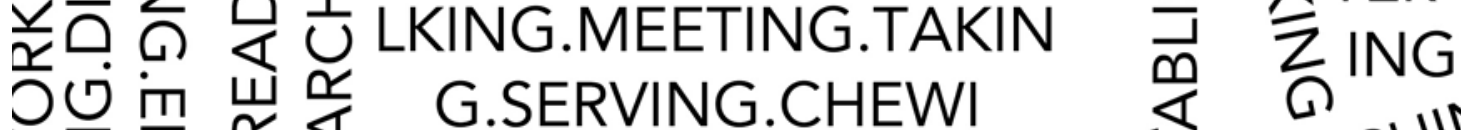

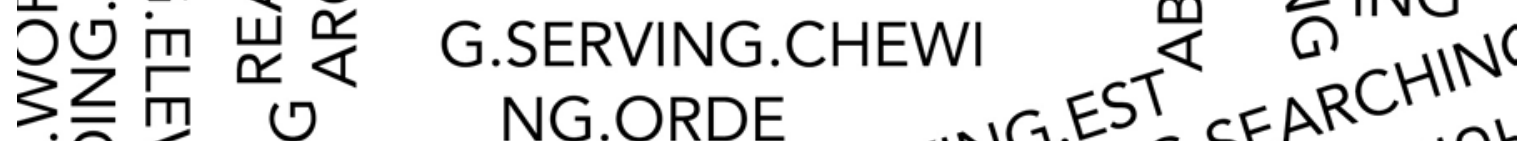

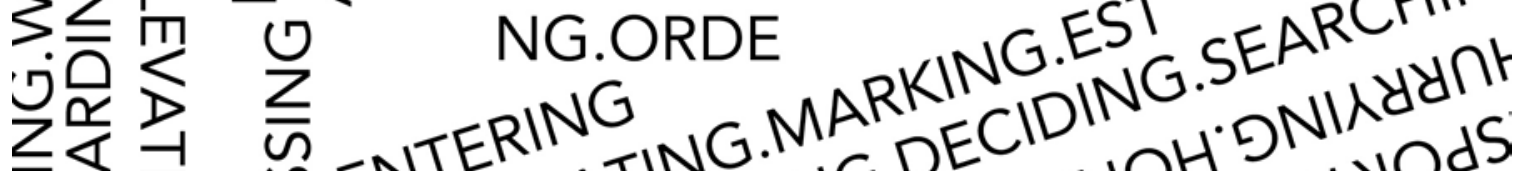
至 תO Q O DELINEATOOKING.D DNIXNOW.DNILYITY

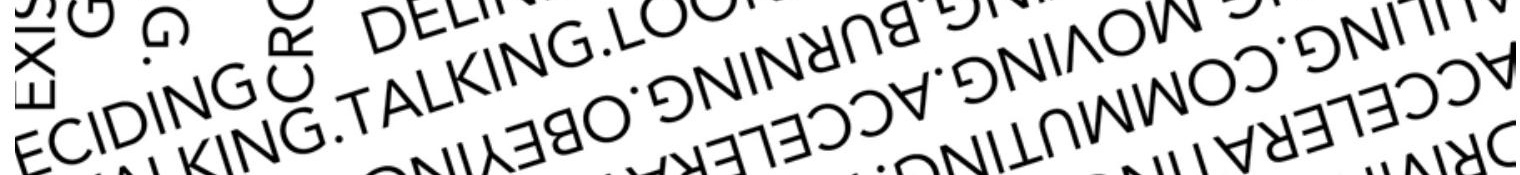




\section{PARTICIPATION}

NECESSARY

Act 10 | Further Reading

ввоск KLasseN

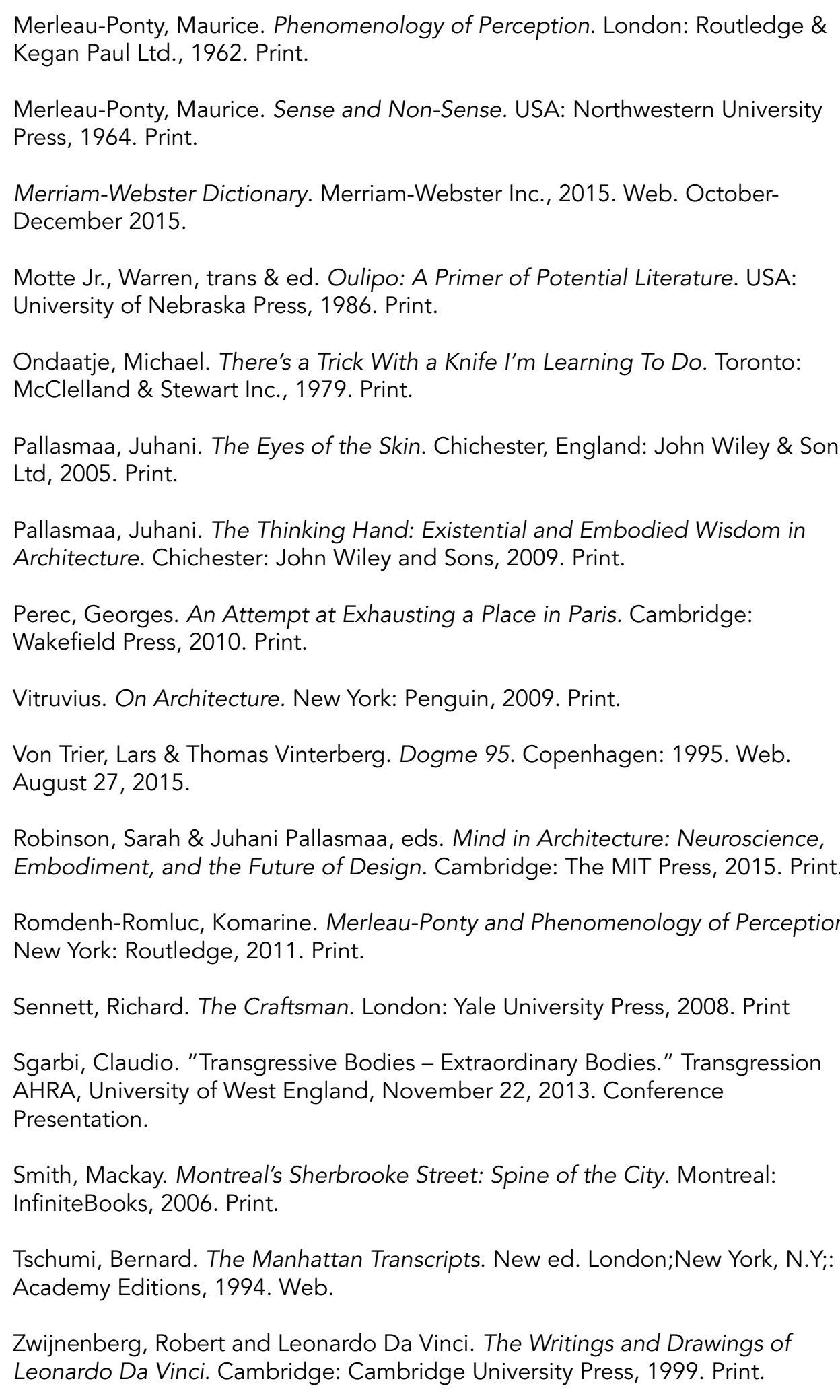

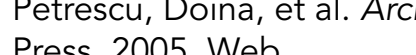

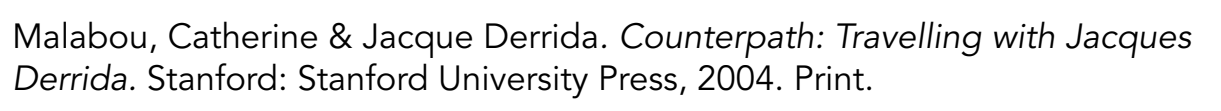

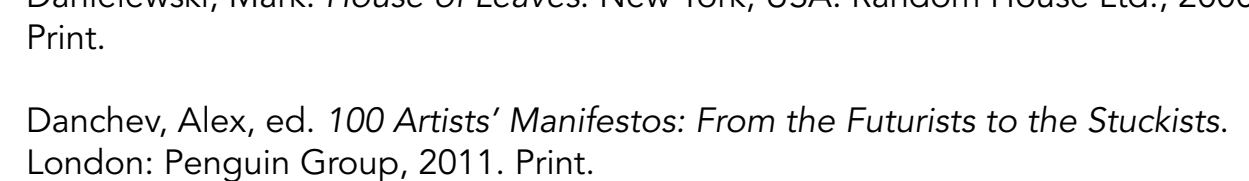

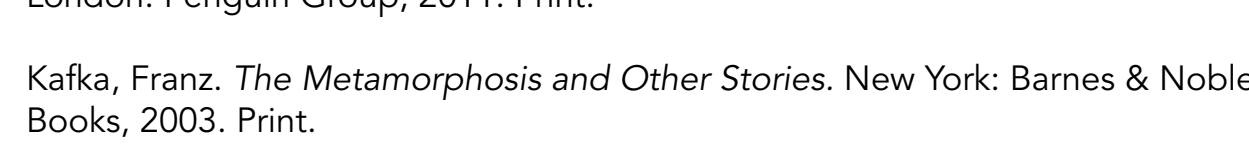

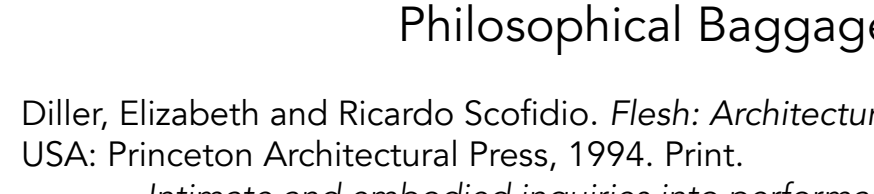

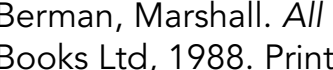

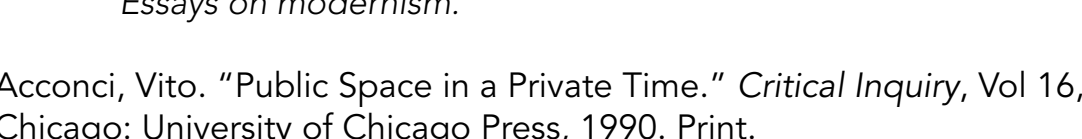

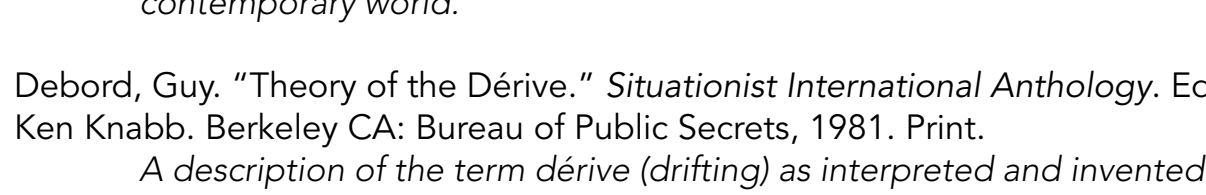

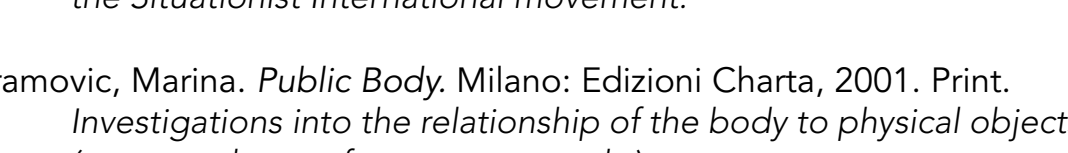

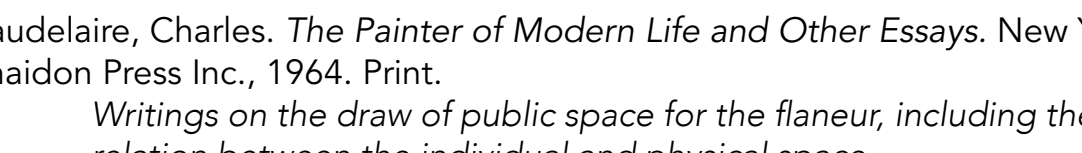

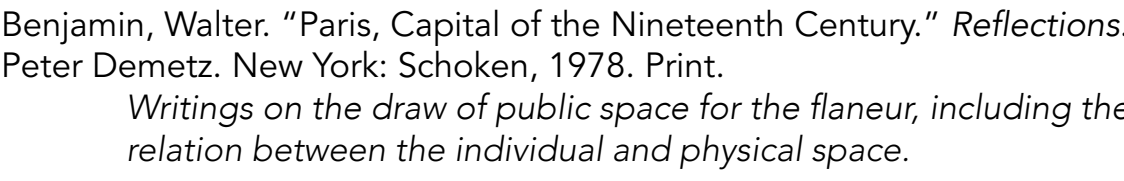

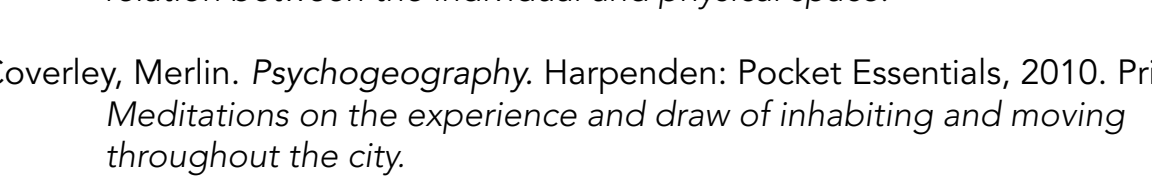

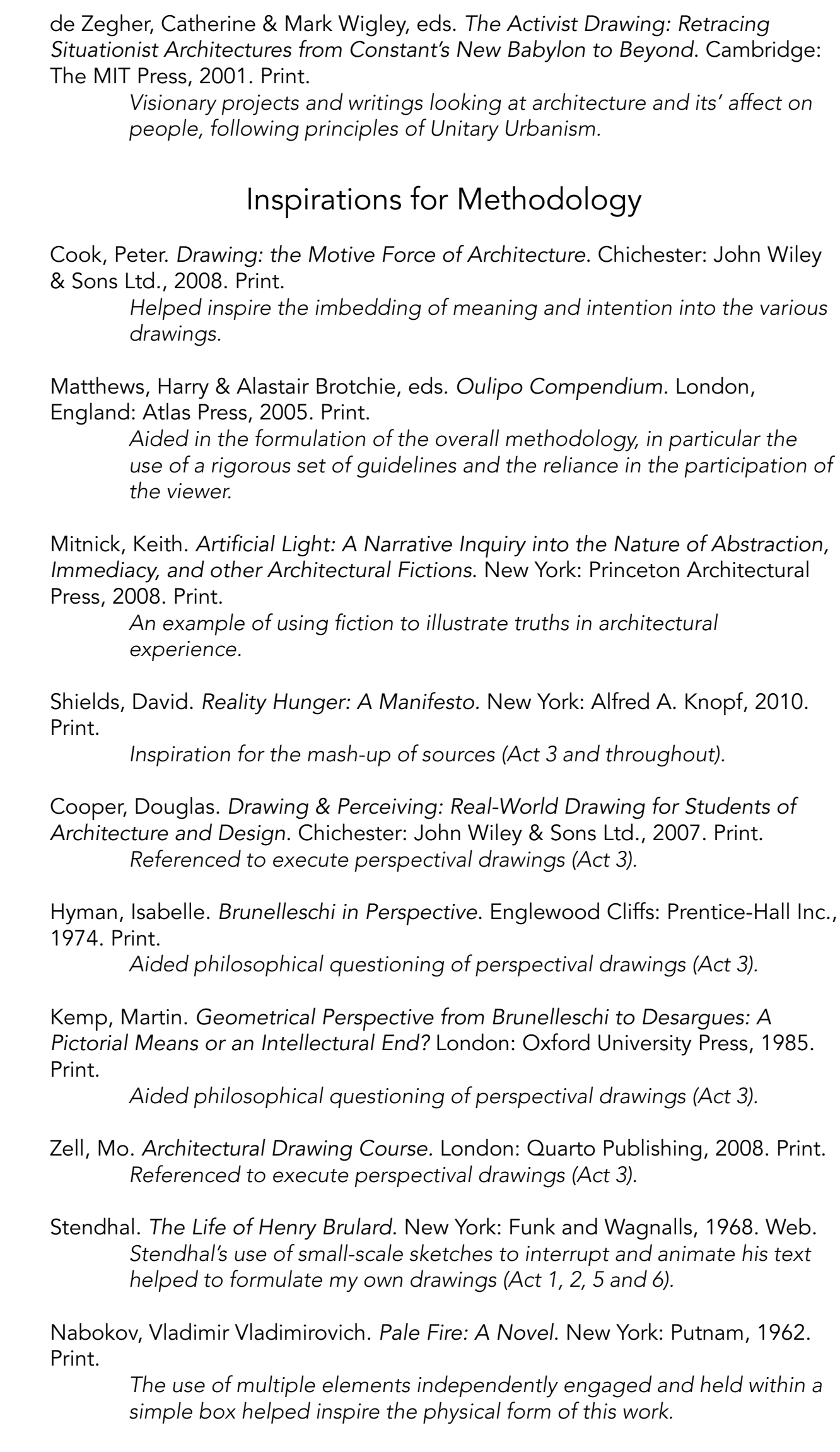




\section{Coda | (Inter)Sections \& Interpretations}

\section{Coda I noun I co-da}

1a: a concluding musical section that is formally distinct from the main structure $1 \mathrm{~b}$ : a concluding part of a literary or dramatic work

2: something that serves to round out, conclude, or summarize and usually has its own interest

(Merriam-Webster Online) 



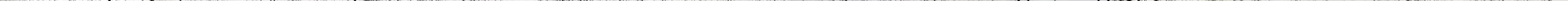




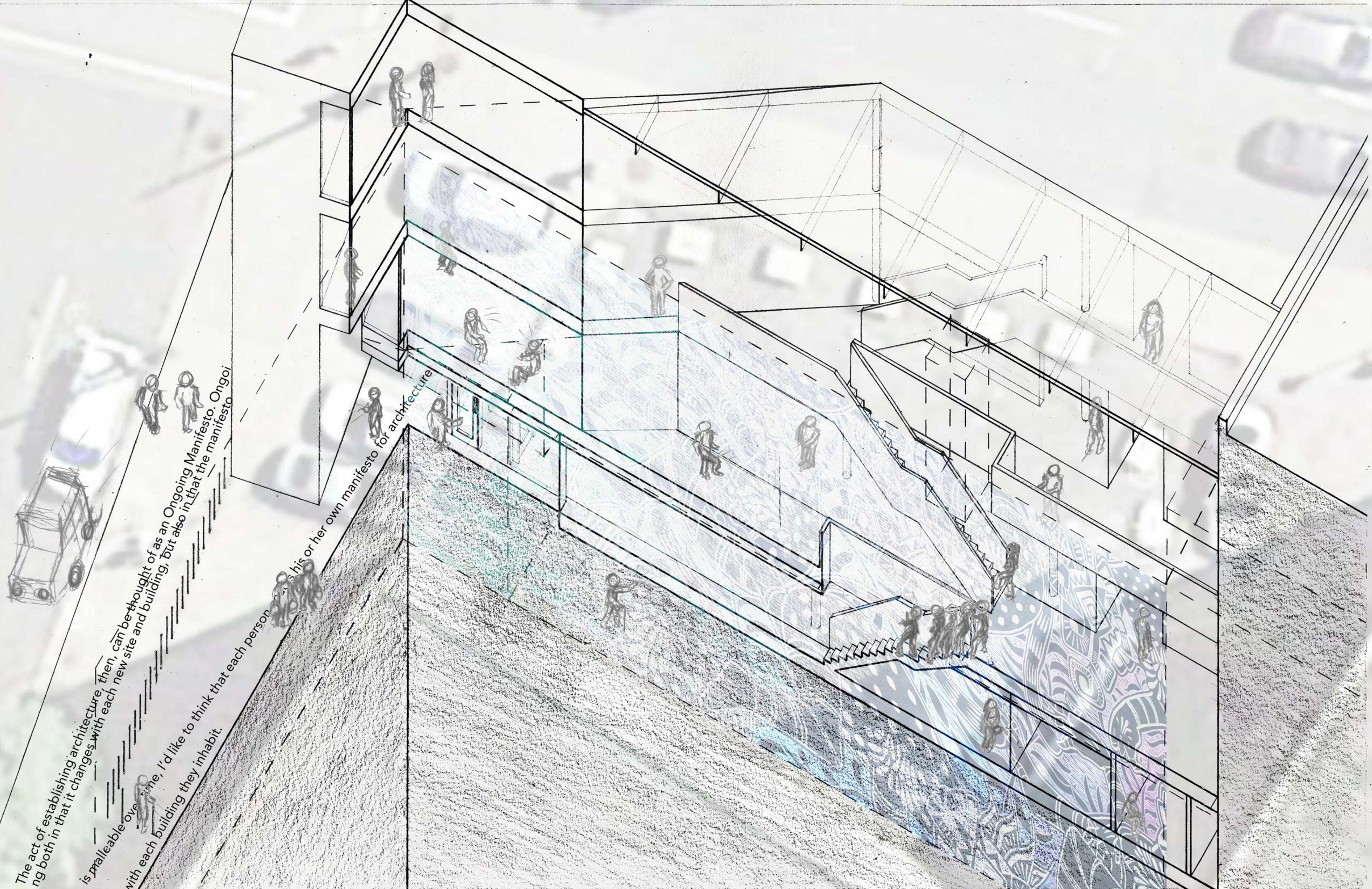

